\title{
Micromonospora olivasterospora sp. nov.
}

\author{
ISAO KAWAMOTO,* MITSUYOSHI YAMAMOTO, AND TAKASHI NARA \\ Tokyo Research Laboratory, Kyowa Hakko Co., 3-6-6 Asahimachi, Machidashi, Tokyo 194, Japan
}

A new species of bacteria is described, for which we propose the name Micromonospora olivasterospora. This organism produces new aminoglycoside antibiotics (the fortimicin complex) and is characterized by its olive black spore layer, spores with blunt spiny surfaces, an olive green soluble pigment, and its carbon utilization pattern. The type strain of $M$. olivasterospora is MK70 (= ATCC 21819).

In the course of screening for new antibiotics, workers isolated an actinomycete (strain MK70) which produced the fortimicin complex $(12,13$; T. Nara, S. Takasawa, R. Okachi, I. Kawamoto, M. Yamamoto, S. Sato, and T. Sato, U.S. patent 3,976,768, August 1976), (pseudodisaccharides consisting of fortamine and purpurosamine sugar). This organism was found to belong to the genus Micromonospora Orskov by morphological and chemotaxonomic studies. In this report we describe this organism and discuss its taxonomic position.

\section{MATERIALS AND METHODS}

Bacterial strains. Strain MK70 was isolated in our laboratory from a soil sample collected in Hiroshima City, Hiroshima Prefecture, Japan. The following type strains were compared with our new isolate: Micromonospora echinospora subsp. echinospora NRRL 2985 (= ATCC 15837), Micromonospora echinospora subsp. ferruginea NRRL 2995 (= ATCC 15836), Micromonospora echinospora subsp. pallida NRRL 2996 (= ATCC 15838), and Micromonospora purpurea NRRL 2953 (= ATCC 15835). Each organism was inoculated into a seed medium, which consisted of $2 \%$ glucose (Nakarai Chemical Co.), $0.2 \%$ beef extract (Kyokuto Seiyaku Co.), $0.2 \%$ yeast extract (Daigo Eiyo Chemical Co.), $0.2 \%$ polypeptone (Daigo Eiyo Chemical Co.), and $0.1 \% \mathrm{CaCO}_{3}$ (Kanto Chemical Co.). The $\mathrm{pH}$ was adjusted to 7.3 before autoclaving. After 2 to 3 days of incubation at $28^{\circ} \mathrm{C}$ on a reciprocating shaker, each culture was centrifuged, washed three times with sterile saline water, and then used as an inoculum for various studies.

Morphological characterization. The spore and mycelial morphologies of cultures grown on American Type Culture Collection (ATCC) medium 5 (1), Hickey-Tresner agar medium (17), and yeast extract malt extract agar medium (International Streptomyces Project [ISP] medium 2) (14) were studied by light microscopy and electron microscopy (model JEM-100C electron microscope; JEOL Ltd.). The spores and mycelia were fixed with osmium tetroxide and were embedded in Epon 812 as described by Leudemann and Casmer (11). Thin sections were cut with glass knives on a model JUM-7 microtome (JEOL Ltd.) and were stained with uranyl acetate and lead citrate.
Cultural characteristics. Cultural characteristics were determined on ISP media, as described by Shirling and Gottlieb (14), and on several media recommended by Waksman (17). Inoculations were made by the method of Shirling and Gottlieb (14). Cultures were incubated at $28^{\circ} \mathrm{C}$ for 2 weeks. The colors of cultures were determined by comparing them with color chips from the Color Harmony Manual (2).

Physiological tests. The media used for physiological characterization of strains were prepared by the methods of Waksman (17) and Shirling and Gottlieb (14). In addition, the medium of Gordon and Smith (3) was used to determine melanoid pigment production. All cultures except those in milk and cellulose were incubated at $28^{\circ} \mathrm{C}$ for 2 weeks; cultures in milk and cultures in cellulose were incubated for 1 month. The temperature and $\mathrm{pH}$ for optimal growth were determined in the seed medium described above after 5 days of incubation.

Carbon utilization. Utilization of carbohydrates was studied by the procedure of Luedemann and Brodsky (10). In addition, a chemically defined medium described elsewhere (I. Kawamoto, T. Oka, and T. Nara, Agric. Biol. Chem., in press) was used as a basal medium in this study.

Chemical analysis of cell components. Phospholipids were examined by the method of Komura et al. (5). The fatty acid spectrum was determined by gas chromatography after transesterification with diazomethane. The instruments used were a Perkin-Elmer model 900 gas chromatograph equipped with a dual-flame ionization detector and a JEOL model OISG-2 mass spectrograph coupled to a JEOL model $20 \mathrm{~K}$ gas chromatograph.

Antibiotic susceptibility. Inocula were streaked onto the surfaces of plates containing ATCC medium 5 (1) and twofold dilutions of antibiotics. The minimal inhibitory concentration (MIC) of each antibiotic was determined after 6 days of incubation at $28^{\circ} \mathrm{C}$.

\section{RESULTS}

Morphology. No true aerial mycelium was produced by strain MK70. The substrate mycelium was well developed, branched, septate, and approximately $0.5 \mu \mathrm{m}$ in diameter. Terminal or intercalary chlamydospore-like swellings were sometimes observed. These swellings were glo- 


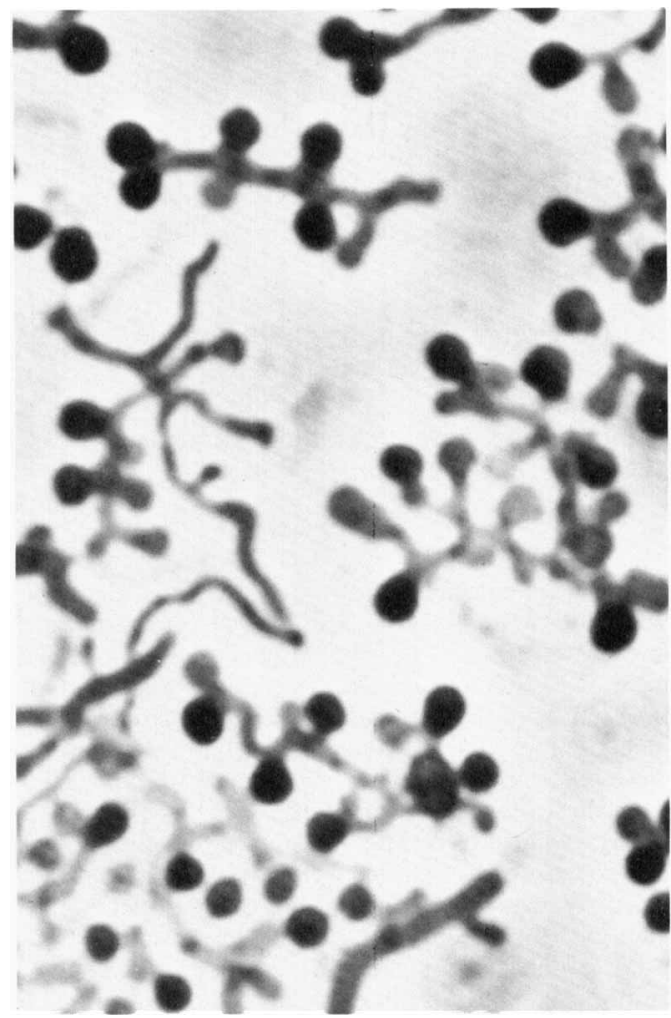

FIG. 1. Spore-bearing substrate mycelium of strain MK70 on ATCC medium 5. Optical microscopy. $\times 4,000$.

bose or oval and were 1.0 to $5.0 \mu \mathrm{m}$ in diameter. The spores were borne singly from the substrate mycelium, usually on short sporophores $(0.3$ to $1.0 \mu \mathrm{m}$ long), or occasionally they were sessile. Apparent branching of the sporophores was also observed. The mature spores were approximately $1.0 \mu \mathrm{m}$ in diameter, nonmotile, and spherical to oval in shape, with a large number of surface projections (0.1 to $0.2 \mu \mathrm{m}$ long). Sclerotium formation and sporangium formation were not observed (Fig. 1 to 4 ).

Cultural characteristics. Table 1 lists the cultural characteristics of strain MK70. Growth was good on most of the organic media used, and the colors of colonies were light brown or dark yellow, turning to olive or dark green during the formation of spores. Olive green soluble pigments were produced in ISP media 2 and 3 and were not acid-alkaline indicators.

Physiological characteristics. The positive physiological properties of strain MK70 included peptonization of skim milk, hydrolysis of starch, and reduction of nitrate. The negative properties included coagulation of skim milk, formation of tyrosinase, and production of melanin. Liquefaction of gelatin and decomposition of cellulose were weakly positive. Optimal growth was observed between $\mathrm{pH} 6.8$ and 7.8 and between 28 and $38^{\circ} \mathrm{C}$.

Carbon utilization. In both Luedemann medium and chemically defined medium, good growth was observed with $\mathrm{D}$-xylose, D-ribose, D-fructose, D-galactose, D-mannose, maltose, sucrose, $\alpha$-trehalose, and starch, but no growth was obtained with $\mathrm{D}$-arabinose, $\mathrm{L}$-rhamnose, Lsorbose, lactose, $\alpha$-melibiose, melezitose, raffinose, glycerol, dulcitol, inositol, sorbitol, mannitol, and salicin. Cellobiose was utilized poorly in the defined medium and moderately in Luedemann medium.

Antibiotic susceptibility. Strain MK70 was susceptible to rifampicin (MIC, $3.13 \mu \mathrm{g} / \mathrm{ml}$ ), chloramphenicol $(6.25 \mu \mathrm{g} / \mathrm{ml})$, chlortetracycline $(3.13$ $\mu \mathrm{g} / \mathrm{ml})$, mitomycin $\mathrm{C}(0.39 \mu \mathrm{g} / \mathrm{ml})$, penicillin $\mathrm{G}$ $(6.25 \mu \mathrm{g} / \mathrm{ml})$, and ristocetin $(1.56 \mu \mathrm{g} / \mathrm{ml})$ and moderately susceptible to spiramycin $(25 \mu \mathrm{g} / \mathrm{ml})$ and cycloserine $(25 \mu \mathrm{g} / \mathrm{ml})$. As shown in Table 2, strain MK70 was resistant to the aminoglycoside antibiotics fortimicin A (MIC, $250 \mu \mathrm{g} / \mathrm{ml}$ ), kanamycin A $(500 \mu \mathrm{g} / \mathrm{ml})$, seldomycins $(500 \mu \mathrm{g} / \mathrm{ml})$, and spectinomycin $(500 \mu \mathrm{g} / \mathrm{ml})$, but was susceptible to neomycins $(0.25 \mu \mathrm{g} / \mathrm{ml})$ and streptomycin A $(0.125 \mu \mathrm{g} / \mathrm{ml})$.

Phospholipids and fatty acids. The phospholipids in whole cells of strain MK70 consisted mainly of bisphosphatidylglycerol, phosphatidylethanolamine, phosphatidylinositol, and phosphatidylinositol mannosides, which were detected in a ratio of 0.21:1.00:0.52:0.74 (measured as phosphorous). The fatty acids in the total cellular lipid consisted of acids having 14 to 18 carbons, most of which were saturated and branched, such as iso-, anteiso- and 10-methyl fatty acids. Isopentadecanoic acid and isohexadecanoic acid were the predominant acids (Fig. $5)$.

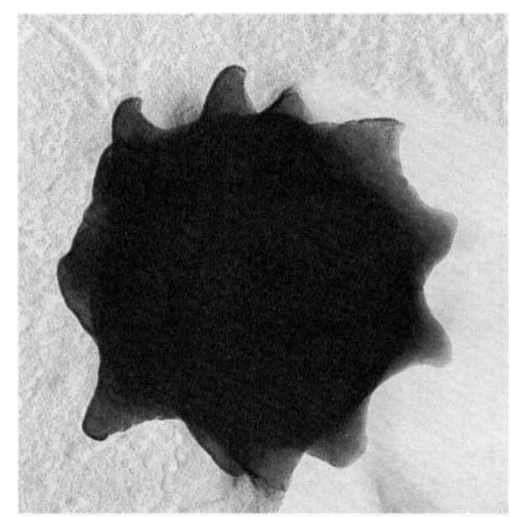

FIG. 2. Blunt spiny spore of strain MK70 on yeast extract malt extract agar medium. Transmission electron microscopy. $\times 40,000$. 


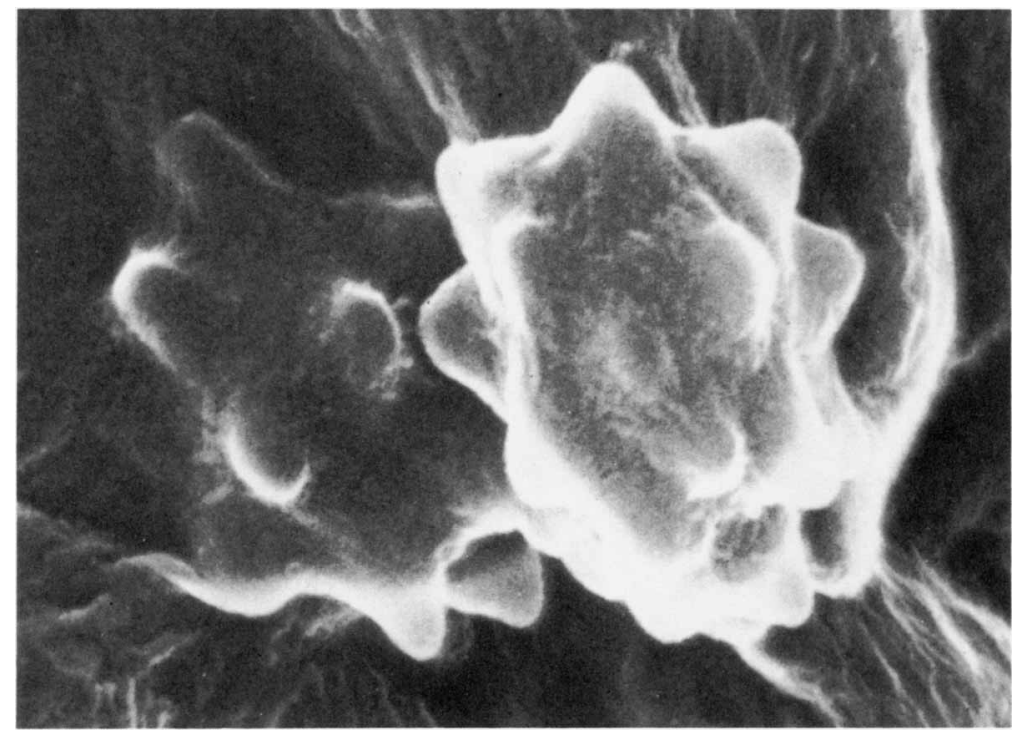

FIG. 3. Blunt spiny spore of strain MK70 on Hickey-Tresner agar medium. Scanning electron microscopy. $\times 58,000$.

\section{DISCUSSION}

Strain MK70 produced spores singly on substrate mycelia and did not form any true aerial mycelium. The cell walls of this strain contained 3-hydroxy-meso-diaminopimelic acid, glycine, arabinose, and xylose (4) and belong to cell wall type II and sugar pattern D in the classification scheme of Lechevalier and Lechevalier (8). The phospholipid composition of strain MK70 had the same pattern as the phospholipid compositions of the Micromonospora strains investigated by Lechevalier et al. (7) and belongs to type II in the classification scheme of Lechevalier et al. (7). The strain MK70 fatty acid pattern, which was positive for iso-, anteiso- and 10methyl acids but negative for unsaturated acids, was the same as the fatty acid patterns of the Micromonospora strains studied by Kroppenstedt and Kustzner (6). Thus, the morphological and chemotaxonomic characteristics of strain MK70 place it in the genus Micromonospora Orskov.

Compared with the known Micromonospora species described in the Approved Lists of Bacterial Names (15) and in Bergey's Manual of Determinative Bacteriology, 8th ed. (9), strain MK70 most closely resembled $M$. echinospora subsp. echinospora Luedemann and Brodsky 1964 (10), M. echinospora subsp. ferruginea Luedemann and Brodsky 1964 (10), and $M$. echinospora subsp. pallida Luedemann and Brodsky 1964 (10) with respect to formation of blunt spiny spores, failure to utilize $\alpha$-melibiose, and the presence of 3-hydroxydiaminopimelic acid in the cell wall. Therefore, a further comparison was made with the type strains of these taxa (M. echinospora subsp. echinospora NRRL 2985 [= ATCC 15837], M. echinospora subsp. ferruginea NRRL 2995 [ = ATCC 15836], and M. echinospora subsp. pallida NRRL 2996 [= ATCC 15838]). Strain MK70 formed olive to olive black spore layers, whereas the type strains of the three subspecies produced purplish black or dark brown to black spore layers. Strain MK70 produced olive to olive green soluble pigments in ISP media 2 and 3, but the other strains did not. The previously described type strains utilized L-rhamnose, but strain MK70 did not. Strain MK70 had no $\beta$-xylosidase activity, but the other strains gave positive or weakly positive test results (Kawamoto et al., in press). Strain MK70 was considerably more susceptible to sagamicin and more resistant to penicillin G than the three strains of $M$. echinospora (Table 2). In addition, strain MK70 did not produce a diagnostic mycelial pigment, but $M$. echinospora subsp. echinospora NRRL $2985^{\mathrm{T}}$ and $M$. echinospora subsp. ferruginea NRRL $2995^{\mathrm{T}}$ produced dark purple to maroon pigments, which were reported to have antibacterial activity against gram-positive bacteria, to be extractable in acidic alcohols, and to be $\mathrm{pH}$ indicators (10). Thus, strain MK70 differs from the three strains of $M$. echinospora in several cultural and physiological properties.

Strain MK70 differs from $M$. purpurea Luedemann and Brodsky $1964\left(\mathrm{NRRL} 2953^{\mathrm{T}}=\right.$ ATCC $\left.15835^{\mathrm{T}}\right)(10)$ and Micromonospora rhodorangera Wagman et al. $1974\left(\right.$ NRRL $5326^{\mathrm{T}}=$ ATCC 

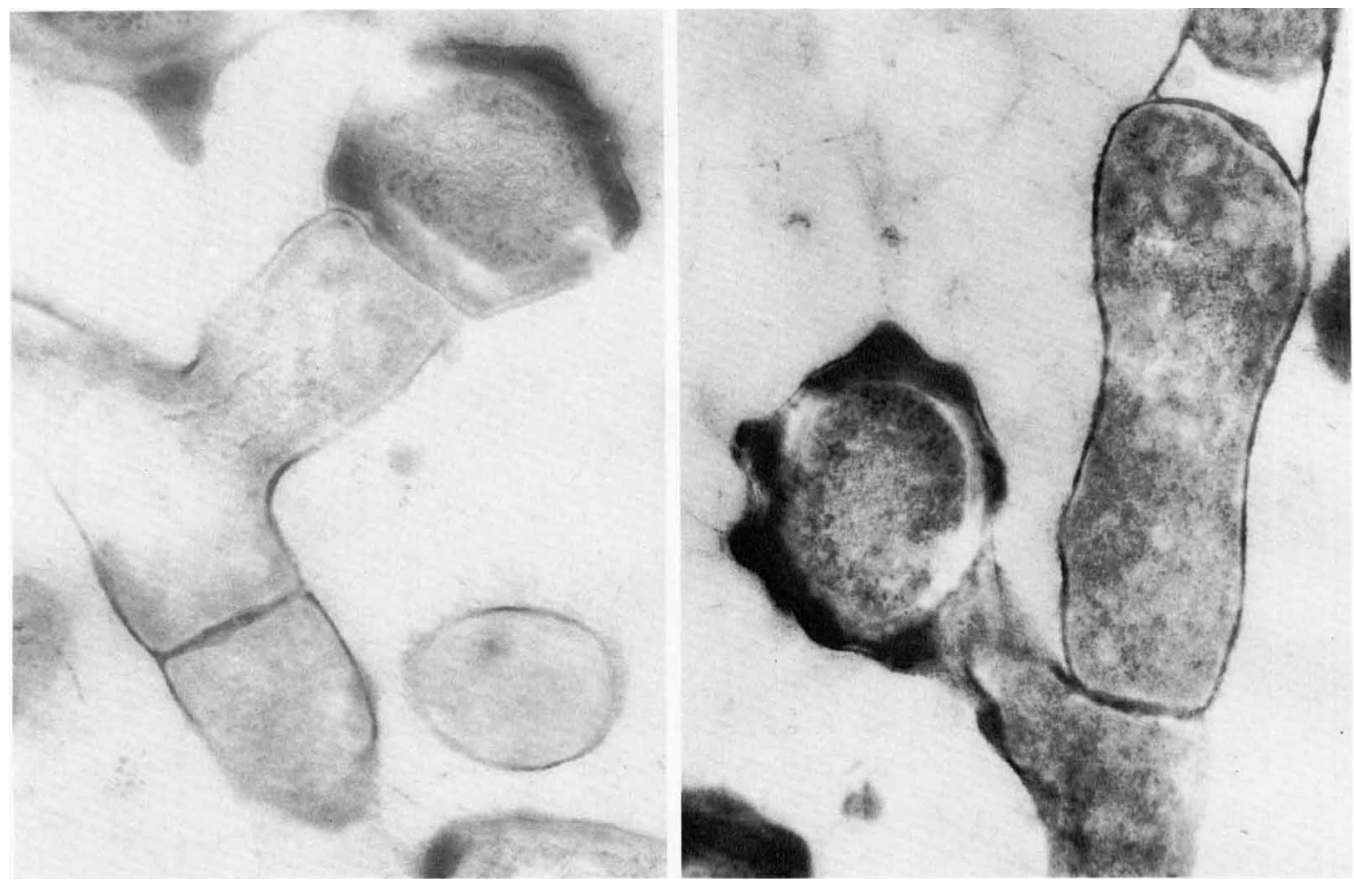

FlG. 4. Thin section of spores and mycelium of strain MK70 on yeast extract malt extract agar medium. Transmission electron microscopy. $\times 50,000$.

$\left.27932^{\mathrm{T}}\right)(16)$, which reportedly do not utilize $\mathrm{L}-$ rhamnose, in that these two species produce purple or red mycelial pigments. Furthermore, the type strains of these species were nonsporulating. Therefore, they lack a morphologically diagnostic character of the genus Micromonospora. On the basis of the information described above, we believe that strain MK70 represents a new species of Micromonospora, for which we propose the name $M$. olivasterospora. A description of the new species is given below.

Micromonospora olivasterospora sp. nov. (o.li. vas.ter.o'spo.ra. L. oliva an olive; Gr. aster a star; Gr. spora a seed; olivasterospora olivecolored spore that looks like a star.)

Spore morphology. Spores at maturity are spherical to oval, approximately $1.0 \mu \mathrm{m}$ in diameter, and appear to be rough when they are examined under a phase-contrast microscope. The roughness appears to be due to a large number of projections, which are 0.1 to $0.2 \mu \mathrm{m}$ long. Spores are produced on short sporophores or are sessile and occur randomly throughout the mycelial webs or in clusters within 3 to 5 days after transfer onto suitable media. Terminal and intercalary chlamydospore-like swellings are sometimes present.

Color of colonies. Young vegetative colonies are light brown or dark yellow and later are covered with an olive or dark green waxy, lustrous layer of spores. Olive green soluble pigments are produced in ISP media 2 and 3 and are not $\mathrm{pH}$ indicators.

Physiological characteristics. Starch is hydrolyzed, and gelatin is weakly liquefied. Skim milk is peptonized but not coagulated. Cellulose is weakly decomposed. Melanoid pigment is not produced. Nitrate reduction is positive. Good growth occurs between 28 and $38^{\circ} \mathrm{C}$; no growth occurs at $47^{\circ} \mathrm{C}$. Good growth occurs between $\mathrm{pH}$ 6.8 and 7.8 ; no growth at $\mathrm{pH} 9.5$ or 5.0.

Carbon utilization. Good growth occurs on D-xylose, D-ribose, D-fructose, D-glucose, D-galactose, D-mannose, maltose, sucrose, $\alpha$ trehalose, and starch. No growth occurs on Darabinose, L-rhamnose, L-sorbose, lactose, $\alpha$ melibiose, melezitose, raffinose, glycerol, dulcitol, inositol, sorbitol, mannitol, and salicin. Cellobiose is utilized moderately in yeast extract medium, but poorly in chemically defined medium containing $\mathrm{NH}_{4} \mathrm{NO}_{3}$ as the nitrogen source.

Nitrogen source. Good growth occurs on $\mathrm{NH}_{4} \mathrm{NO}_{3},\left(\mathrm{NH}_{4}\right)_{2} \mathrm{SO}_{4}, \mathrm{NH}_{4} \mathrm{Cl}$, L-serine, L-aspartic acid, L-glutamic acid, L-histidine, and $\mathrm{L}$-arginine; no growth occurs on $\mathrm{L}$-alanine, $\mathrm{L}$ valine, L-homoserine, L-methionine, L-phenylalanine, L-tyrosine, and L-tryptophan.

Glycosidase activity. Activity is detectable with $\alpha$-glucosidase, $\beta$-glucosidase, $\beta$-galactosidase, and $\beta-N$-acetylglucosaminidase, but not 
TABLE 1. Cultural characteristics of strain MK70

\begin{tabular}{|c|c|c|c|}
\hline Medium & Growth & Color $^{a}$ & $\begin{array}{l}\text { Soluble } \\
\text { pigment }\end{array}$ \\
\hline Sucrose nitrate agar & Moderate, flat & Dusty olive (1 lg) & None \\
\hline Glucose asparagine agar & $\begin{array}{l}\text { Moderate, flat, } \\
\text { waxy }\end{array}$ & Olive $(1 \mathrm{ni})$ & None \\
\hline $\begin{array}{l}\text { Inorganic salts starch agar (ISP } \\
\text { medium 5) }\end{array}$ & Good, flat & Black olive (i po) & None \\
\hline Egg albumin agar & $\begin{array}{l}\text { Moderate, flat, } \\
\text { waxy }\end{array}$ & Light olive drab (1 li) & None \\
\hline Nutrient agar & Good, raised, ridged & Olive $(1 \mathrm{pl})$ & None \\
\hline $\begin{array}{l}\text { Yeast extract malt extract agar } \\
\text { (ISP medium 2) }\end{array}$ & Good, raised, ridged & Dark olive (1 pn) & $\begin{array}{c}\text { Dark olive } \\
\text { (11/2 pn) }\end{array}$ \\
\hline Oatmeal agar (ISP medium 3) & Good, plicate & $\begin{array}{l}\text { Butterscotch }(3 \mathrm{lc}) \text { to } \\
\text { dark brown }(2 \mathrm{pn})\end{array}$ & $\begin{array}{l}\text { Dusty olive } \\
\text { (i pg) }\end{array}$ \\
\hline Bennett agar & Good, raised, ridged & Dark olive (1 pn) & None \\
\hline Emerson agar & $\begin{array}{l}\text { Moderate, waxy, } \\
\text { raised, ridged }\end{array}$ & Olive $(1 \mathrm{ni})$ & None \\
\hline Glucose yeast extract agar & $\begin{array}{l}\text { Good, waxy, raised, } \\
\text { ridged }\end{array}$ & Dark olive (1 pn) & None \\
\hline Tyrosine agar (ISP medium 7) & Moderate, flat & Mustard tan $(2 \mathrm{lg})$ & None \\
\hline Tyrosine agar $^{b}$ & $\begin{array}{l}\text { Moderate, flat, } \\
\text { waxy }\end{array}$ & Olive (1 ni) & None \\
\hline $\begin{array}{l}\text { Peptone yeast extract iron agar } \\
\text { (ISP medium 6) }\end{array}$ & $\begin{array}{l}\text { Moderate, flat, } \\
\text { waxy }\end{array}$ & Dark olive $(1 \mathrm{nl})$ & None \\
\hline
\end{tabular}

${ }^{a}$ The color codes and names used in this study are from the Color Harmony Manual, 4th ed. (2).

${ }^{b}$ The medium of Gordon and Smith (3).

with $\alpha$-galactosidase, $\alpha$-xylosidase, $\beta$-xylosidase, $\alpha$-mannosidase, $\alpha$-fucosidase, $\beta$-fucosidase, and $\beta$-glucuronidase.

Antibiotic susceptibility. The type strain is susceptible to rifampicin (MIC, $3.13 \mu \mathrm{g} / \mathrm{ml}$ ), chloramphenicol $(6.25 \mu \mathrm{g} / \mathrm{ml})$, chlortetracycline $(3.13 \mu \mathrm{g} / \mathrm{ml})$, mitomycin C $(0.39 \mu \mathrm{g} / \mathrm{ml})$, penicillin $G(6.25 \mu \mathrm{g} / \mathrm{ml})$, ristocetin $(1.56 \mu \mathrm{g} / \mathrm{ml})$, streptomycin A $(0.125 \mu \mathrm{g} / \mathrm{ml})$, and neomycins $(0.25$ $\mu \mathrm{g} / \mathrm{ml}$ ). This strain is moderately susceptible to spiramycin $(25 \mu \mathrm{g} / \mathrm{ml})$, cycloserine $(25 \mu \mathrm{g} / \mathrm{ml})$, and sagamicin $(31.2 \mu \mathrm{g} / \mathrm{ml})$ and resistant to gentamicin $C$ complex $\left(\mathrm{C}_{1}, \mathrm{C}_{2}\right.$, and $\left.\mathrm{C}_{1 \mathrm{a}} ; 125 \mu \mathrm{g} / \mathrm{ml}\right)$, fortimicin A $(250 \mu \mathrm{g} / \mathrm{ml})$, kanamycin A $(500$ $\mu \mathrm{g} / \mathrm{ml})$, seldomycins $(500 \mu \mathrm{g} / \mathrm{ml})$, and spectinomycin $(500 \mu \mathrm{g} / \mathrm{ml})$.

$\mathrm{NaCl}$ tolerance. Growth is reduced at an $\mathrm{NaCl}$ concentration of $3 \%$ and does not occur at $4 \%$ $\mathrm{NaCl}$.

Cell wall composition. Glycine, 3-hydroxymeso-diaminopimelic acid, glutamic acid, and Dalanine occur in the cell wall in a molar ratio of 1.00:1.16:0.926:0.58. Glycolic acid occurs in the peptidoglycan, and its molar ratio to 3-hydroxydiaminopimelic acid is ca. $\mathbf{0 . 7 6 8}$. Xylose, arabinose, and glucose are the predominant sugars in the cell walls.

Phospholipid and fatty acid. Bisphosphatidyl-

TABLE 2. Susceptibilities to antibiotics

\begin{tabular}{|c|c|c|c|c|c|c|c|c|c|c|}
\hline \multirow[b]{2}{*}{ Strain } & \multicolumn{10}{|c|}{ MIC $(\mu \mathrm{g} / \mathrm{ml})$ of: } \\
\hline & $\begin{array}{l}\text { Forti- } \\
\text { micin A }\end{array}$ & $\begin{array}{l}\text { Saga- } \\
\text { micin }\end{array}$ & $\begin{array}{l}\text { Gentamicin } \\
\text { C complex }\end{array}$ & $\begin{array}{c}\text { Kana- } \\
\text { mycin A }\end{array}$ & $\begin{array}{l}\text { Seldo- } \\
\text { mycins }\end{array}$ & $\begin{array}{c}\text { Neo- } \\
\text { mycins }\end{array}$ & $\begin{array}{c}\text { Strepto- } \\
\text { mycin A }\end{array}$ & $\begin{array}{c}\text { Spectino- } \\
\text { mycin }\end{array}$ & $\begin{array}{c}\text { Mito- } \\
\text { mycin C }\end{array}$ & $\begin{array}{l}\text { Peni- } \\
\text { cillin } \\
\text { G }\end{array}$ \\
\hline M. purpurea NRRL $2953^{\mathrm{T}}$ & 250 & 2,000 & 500 & 4,000 & 500 & 0.5 & 8.0 & 500 & 6.25 & $0 . \overline{10}$ \\
\hline $\begin{array}{l}\text { M. echinospora subsp. } \\
\text { echinospora NRRL } 2985^{\mathrm{T}}\end{array}$ & 4,000 & 8,000 & 1,000 & 4,000 & 1,000 & 1.0 & 8.0 & 500 & 3.12 & 0.10 \\
\hline $\begin{array}{l}\text { M. echinospora subsp. } \\
\text { ferruginea NRRL } 2995^{\mathrm{T}}\end{array}$ & 4,000 & 4,000 & 1,000 & 2,000 & 1,000 & 2.0 & 16.0 & 500 & 6.25 & 0.39 \\
\hline $\begin{array}{l}\text { M. echinospora subsp. } \\
\text { pallida NRRL } 2996^{\mathrm{T}}\end{array}$ & 2,000 & 2,000 & 1,000 & 1,000 & 500 & 1.0 & 0.5 & 500 & 1.56 & 0.10 \\
\hline $\begin{array}{l}\text { Micromonospora sp. strain } \\
\text { MK } 70\end{array}$ & 250 & 31.2 & 125 & 500 & 500 & 0.25 & 0.125 & 500 & 0.39 & 6.25 \\
\hline
\end{tabular}

${ }^{a}$ Gentamicin $C_{1}$, gentamicin $C_{2}$, and gentamicin $C_{1 a}$. 


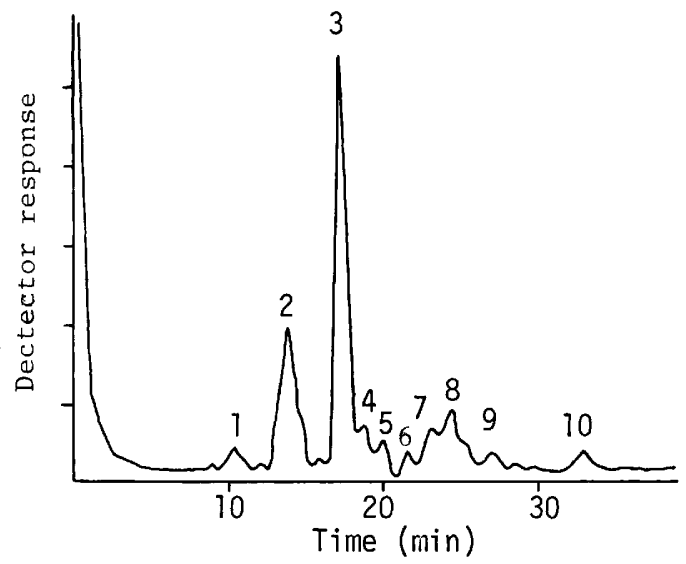

FIG. 5. Gas chromatographic resolution of fatty acid esters from strain MK70. Peak 1 , anteiso- $\mathrm{C}_{14}: 0$; peak 2 , iso- $\mathrm{C}_{15}: 0$; peak 3 , iso- $\mathrm{C}_{16}: 0$; peak 4 , anteiso$\mathrm{C}_{16}: 0$; peak 5, $\mathrm{C}_{16}: 0$; peak 6,10 -methyl- $\mathrm{C}_{17}: 0$; peak 7 , iso- $\mathrm{C}_{17}: 0$; peak 8 , anteiso- $\mathrm{C}_{17}: 0$; peak 9,10 -methyl$\mathrm{C}_{18}: 0$; peak 10 , anteiso- $\mathrm{C}_{18}: 0$.

glycerol, phosphatidylethanolamine, phosphatidylinositol, and phosphatidylinositol mannosides are present in the cells. Most of fatty acids are saturated and branched. The predominant fatty acids are isopentadecanoic acid and isohexadecanoic acid.

Antagonistic properties. The type strain produces fortimicins.

Habitat. This organism occurs in the soil.

Type strains. The type strain is strain MK70. A culture of this strain has been deposited at the ATCC as ATCC 21819. Since the description of $M$. olivasterospora given above is based on a single strain (the type strain), the species description also serves as the description of the type strain.

\section{LITERATURE CITED}

1. American Type Culture Collection. 1982. Catalogue of strains I, 15th ed. American Type Culture Collection, Rockville, Md.
2. Container Corporation of America. 1958. Color harmony manual, 4th ed. Container Corporation of America, Chicago, Ill.

3. Gordon, R. E., and M. M. Smith. 1955. Proposed group of characters for the separation of Streptomyces and Nocardia. J. Bacteriol. 69:147-150.

4. Kawamoto, I., T. Oka, and T. Nara. 1981. Cell wall composition of Micromonospora olivoasterospora, Micromonospora sagamiensis, and related organisms. J. Bacteriol. 146:527-534.

5. Komura, I., K. Yamada, and K. Komagata. 1977. Taxonomic significance of phospholipid composition in aerobic gram-positive cocci. J. Gen. Appl. Microbiol. 21:97-107.

6. Kroppenstedt, R. M., and H. J. Kustzner. 1976. Biochemical marker in the taxonomy of the Actinomycetales. Experientia 30:318-420.

7. Lechevalier, M. P., C. D. Bièvre, and H. A. Lechevalier. 1977. Chemotaxonomy of aerobic actinomycetes: phospholipid composition. Biochem. Syst. Ecol. 5:249-260.

8. Lechevalier, M. P., and H. A. Lechevalier. 1970. Chemical composition as a criterion in the classification of aerobic actinomycetes. Int. J. Syst. Bacteriol. 20:435-443.

9. Luedemann, G. M. 1974. Genus I. Micromonospora Orskov, p. 846-855. In R. E. Buchanan and N. E. Gibbons (ed.), Bergey's manual of determinative bacteriology, 8 th ed. The Williams \& Wilkins Co., Baltimore.

10. Luedemann, G. M., and B. Brodsky. 1964. Taxonomy of gentamicin-producing Micromonospora, p. 116-124. Antimicrob. Agents Chemother. 1963.

11. Luedemann, G. M., and C. J. Casmer. 1973. Electron microscope study of whole mounts and thin sections of Micromonospora chalcea ATCC 12452 . Int. J. Syst. Bacteriol. 23:243-255.

12. Nara, T., M. Yamamoto, I. Kawamoto, K. Takayama, R. Okachi, S. Takasawa, S. Sato, and T. Sato. 1977. Fortimicins $\mathrm{A}$ and $\mathrm{B}$, new aminoglycoside antibiotics. I. Producing organism, fermentation, and biological properties of fortimicins. J. Antibiot. 30:533-540.

13. Okachi, R., S. Takasawa, T. Sato, S. Sato, M. Yamamoto, I. Kawamoto, and T. Nara. 1977. Fortimicins A and B, new aminoglycoside antibiotics. II. Isolation, physicochemical and chromatographic properties. J. Antibiot. 30:541-551.

14. Shirling, E. B., and D. Gottlieb. 1966. Method for classification of Streptomyces species. Int. J. Syst. Bacteriol. 16:313-340.

15. Skerman, V. B. D., V. McGowan, and P. H. A. Sneath. (ed.). 1980. Approved lists of bacterial names. Int. J. Syst. Bacteriol. 30:225-420.

16. Wagman, G. H., R. T. Testa, J. A. Marquez, and M. J. Weinstein. 1974. Antibiotic G-418, a new Micromonospora-produced aminoglycoside with activity against protozoa and helminths: fermentation, isolation, and preliminary characterization. Antimicrob. Agents Chemother. 6:144-149.

17. Waksman, S. A. 1961 . The actinomycetes, vol. 2. Classification, identification and description of genera and species. The Williams \& Wilkins Co., Baltimore. 